\title{
DEMAND FOR FERTILIZER IN NIGERIA: AN APPLICATION OF COINTEGRATION AND ERROR CORRECTION MODELING
}

\author{
OKOROAFOR $^{1}$, O.N., R.N. ECHEBIRI ${ }^{1}$, AND I.N. NWACHUKWU ${ }^{2}$ \\ ${ }^{1}$ Department of Agricultural Economics, \\ ${ }^{2}$ Department of Agribusiness and Management, Michael Okpara University of \\ Agriculture, Umudike. \\ Email: buchy2002ok@yahoo.com
}

\begin{abstract}
Input-output price ratio is an important factor in the use of purchased farm inputs. Sufficient empirical evidence is needed to guide rational and accurate prediction of fertilizer demand in a predominantly peasant, external input-driven agro-ecosystem. This study employed time series data for the years 1970 to 2005 to estimate relative price elasticities of fertilizer demand in Nigeria using price ratios of fertilizer to cassava. The autoregressive distributed lag error correction model (ARDL-ECM) produced a plausible estimate of short-run and long-run price elasticities of fertilizer demand with respect to the relative price ratio. The ECM coefficient showed a slow adjustment of fertilizer use to the error correction term, indicating that fertilizer use responds slowly to shifts and shocks in the determining variables. This implies that inspite of the inherent difficulties associated with using fertilizers in Nigeria, the farmers still recognize its relevance in crop production as well as the attendant economic benefits. Another plausible finding of the study was the positive correlation between fertilizer use and irrigation. Following these outcomes, it was advocated, in the main, that farmers should be well informed on market opportunities with consideration given to input and output prices. The onus lies in establishing a workable market information system that would provide timely information with respect to spatial and temporal price variations in both input and output markets. In this same vein, emphasis was laid on developing irrigation infrastructure as a major policy thrust for fostering fertilizer use across the country
\end{abstract}

Keywords; Fertilizer, Demand, Error Correction, Cointegration

\section{INTRODUCTION}

Evidence from case studies such as Viyas (1983), Modak et al (1996), Shapiro et al (1998) and IFDC (2002) has demonstrated the dominance of fertilizer-use effect on changes in crop output among developing and developed countries alike. Generally, it has also been emphasized that the success of the Green Revolution in Latin America and Asia, which Eicher (1995) connects to the presence of fertilizer subsidies bears strongly on intensive use of chemical fertilizer. However, fertilizer consumption in Africa stands to be the lowest in the world and this can therefore be attributed as one of the main causes of poor output growth rate of food crops in Nigeria. The search for appropriate policy that will increase the capacity of small-scale farmers in their use of fertilizer remains unsettled. The most recent search for appropriate policy that will increase the fertilizer-use capacity of small-scale farmers was under the torchlight of the African Fertilizer Summit held from 9-15 June 2006 in Abuja, Nigeria. It is in recognition of the steady decline in Africa's per capita food production growth rates that the summit was convened. The basic goal of the summit was to build a consensus around the key issues in increasing fertilizer use in Africa and agree on a strategy for developing an African Fertilizer Action Plan. In a nut shell, the summit was aimed at accelerating the much-needed access to this vital farm input and other external inputs in order to engender farm productivity achieve food security and reduce poverty. 
Studies on fertilizer demand have provided various raison d'eter for the fertilizer demand scenario in Africa. From the economic perspective, farm input demands are derived from the underlying demand for the commodity that the farmer produces. Based on this theoretical underpinning, fertilizer demand depends on the demand for the crops. Unfortunately, the situation in Africa depicts an adverse price ratio of fertilizer to food crops (Timmer, 1986). The implication is that the product price to fertilizer crop price ratio is too low for farmers to invest in fertilizer. This singular factor undermines the production and profit goals of the farmer from the stand point of a regular profit making enterprise. The farmer taking requisite farm investment decision within this realm will certainly push out onto the extensive margin to make up for the gap in production created by low and unprofitable use of fertilizer.

The scenario above succinctly explains the root cause of soil mining and environmental degradation. It describes the negative impact of low level of fertilizer consumption and consequent disappearance of the fallow land. Binswanger (1986) notes that rising population density and declining soil fertility have further aggravated these problems. The state of agricultural production in the country within the 1990 to 2000 period reveals that while the area cultivated under major crops showed positive growth rates, the growth in productivity within this period was low or negative (CBN, 2001). Following the decline in productivity, farmer's income also had constantly been on the decline. With the everincreasing population and dearth of foreign exchange, increasing hectarage cannot continuously raise production and food importation cannot be sustained in the long-run. The low and declining farm income further constrains the capability of farmers in the use of external inputs like fertilizer and improved seeds, hence creating a vicious cycle. The need for sustained fertilizer use therefore deserves an empirical understanding of the relationship between fertilizer demand and its relative price ratios to individual crops in the long-run. It is in this connection that the study was designed to analyze the nature and direction of causation, hence investigating the long-run equilibrium relationship between fertilizer demand and its determining variables. The study also estimated relative price elasticities of fertilizer demand using price ratio of fertilizer to cassava in Nigeria, by applying the Error Correction Model with the partial adjustment nesting within it.

The responsiveness of fertilizer demand to own price and to agricultural price changes are topical issues for the main reason of predictions of fertilizer consumption to changes in product prices. In a fertilizer demand study, Mergos and Stoforos (1997) estimated that though fertilizer demand in Greece responds to changes in fertilizer prices, still it is more responsive to changes in crop output prices and to technology changes that accompany fertilizer use. They concluded that measures affecting product prices are more effective ways of influencing fertilizer demand than measures influencing input prices such as fertilizer subsidy. The above conclusion is anchored on the a priori economic rationale that the producers input demand are derived from the underlying demand for the commodity, which they produce. Another important dimension of fertilizer demand and agricultural output response to price changes has to do with time frame, whether the short-run or the long-run. Since agriculture may respond with considerable lags, long-run supply elasticity will be of higher value with respect to prices and other relative factors than in the short run (Binswanger, 1990). Studies have shown that price elasticities of demand for fertilizer in the developing countries vary from $0.26 \%$ to 0.9 percent in the short run and from $0.8 \%$ to $1.76 \%$ in the long-run (Ogunfowara, 1987).

In developing countries characterized by smallholdings and subsistence farming, fertilizer demand tends to be price sensitive. When the fertilizer price goes up in relation to product price, consumption tends to fall in the short-run until technological adjustment or other factors improve yield response to neutralize the effect of the price increase. In Asian 
countries, for example, a good monsoon can have the effect of tempering the adverse consequence of marginal fertilizer price increases. Similarly, new seed variety shifts yield response upwards, thus mitigating the effect of a fertilizer price increase. Increased credit availability exerts a similar influence. The rising trend in fertilizer consumption in many developing countries, therefore, cannot be fully explained by the input-output price relationship (Parthasarathy, 1994), but could have marginal effects from environmental, agronomic and in addition to some not so obvious socio-economic factors.

Fertilizer demand depends on a variety of agro-economic factors and this increases the difficulty of stable and accurate prediction of its demand. In Nigeria, studies on fertilizer demand position have been carried out mainly on cross sectional basis, like Emerole and Chima (1998) and Tanko (2001), yet a lot more needs to be done to come up with more detailed recommendations on how to build greater capacity for fertilizer use. These studies, based on the analytical approach, did not give room for long-run predictions using the generated results. No doubt, time series has the advantage of providing estimates that will serve for long-run prediction purposes.

Using the time series analytical approach, the factors raised earlier were integrated into an analytical model. The study employed the Autoregressive Distributed Lag Error Correction Model (ARDL-ECM), the use of which can be justified based mainly on two econometric criteria. First, is the need to regress only stationary time series to avoid obtaining misleading estimates arising from non-stationary variables. Mergos et al (1997) employed this concept by carrying out successive differencing of the time series in order to obtain a causal effect arising not just from trend but rather from a meaningful relationship. It was explained by the study that the earlier approaches of using single equation model has its advantage on ease of interpretation and simplicity. Dynamic aspects of fertilizer demand as applied in this study using time series analytical technique is theoretically more plausible and can be applied in prediction outside the sample range. Secondly, farmers as economic agents form expectations of price for year $t$ based on year $t-1$. So, the error correction model with the partial adjustment nesting within differentiates between long-run equilibrium and short-run dynamics by providing estimates for the speed or adjustment coefficient.

The empirical model for this study is conceptualized to capture input to output price ratio effects on fertilizer demand using fertilizer-cassava price ratio and other fertilizer demand determinants. The inclusion of the price of cassava in the model is to capture the relative price effect, that is, input-output price ratio effect on fertilizer demand. Cassava is used in this essence following the widely intensive cultivation of the crop and its overwhelming contribution to aggregate crop production. In this model it is expected that the demand for fertilizer, relative price ratios of fertilizer-cassava (current and lagged), real exchange rate and the absence of subsidy would be negatively related. On the other hand, it is also hypothesized that area of land under irrigation, harvest area, volume of credit, number of tractor in use, annual average rainfall, lagged quantity of fertilizer used and presence of fertilizer subsidy would have positive effect on the quantity of fertilizer used.

\section{MATERIALS AND METHODS \\ Data}

Annual time series data covering the period 1970 to 2005 generated mainly from FAOSTATthe FAO's online agricultural database were used for the estimation. Other complementary sources include Central Bank of Nigeria (CBN), (Statistical Bulletin), Bureau of Statistics (BOS) (Various Issues of Statistics), and Federal Ministry of Agriculture and Rural Development (FMARD). 


\section{Model Specification}

As earlier outlined in the conceptual framework, a general postulated fertilizer demand equation is presented thus:

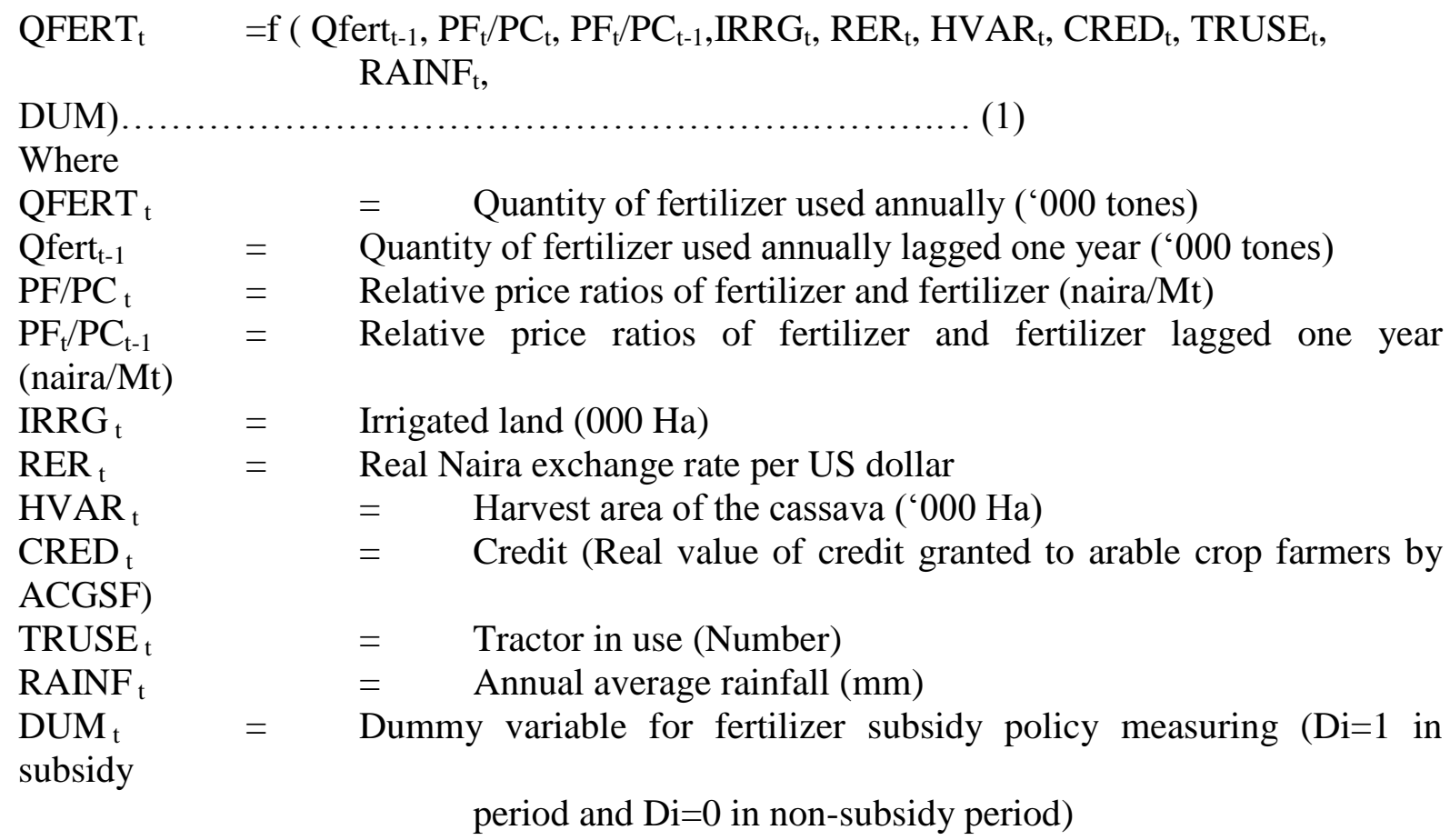

The variable "DUM" is essentially a qualitative variable or a dummy variable. Such variables indicate the presence or absence of an attribute. The qualitative or artificial variable so constructed takes on values of 1 or 0 , whereby 1 indicates the presence of an attribute. In this study, the period of government subsidy on fertilizer takes on the value 1 while non-subsidy period or regime takes on the value 0 .

\section{Estimation Procedure}

The study employed Error Correction Models as suggested by Engle and Granger (1987). There are four steps in the application of the above technique. The first involves carrying out a unit root test on univariate time series to determine the order of integration through successive differencing. Secondly, cointegration regression with OLS method was estimated using variables of the same order of integration. The residuals of the cointegration regression were tested for stationarity in the third step. Lastly, the Error Correction Model (ECM) was estimated.

Step i: Using the Augmented Dickey- Fuller (ADF) test (Dickey and Fuller, 1976) with seasonal and constants, the order of integration of each time series variable was tested. The $\mathrm{ADF}$ test for this study is formulated by these equations:

\begin{tabular}{|c|c|c|}
\hline$\triangle \mathrm{HVAR}_{\mathrm{t}}$ & $=$ & $\begin{array}{l}\phi_{0}+\phi_{\mathrm{t}} \mathrm{HVAR}_{\mathrm{t}-1}+\sum \mathrm{d}_{\mathrm{i}} \Delta \mathrm{HVAR}_{\mathrm{t}-\mathrm{i}}+\varepsilon_{\mathrm{t}} \ldots \ldots \ldots \ldots \ldots \ldots \ldots \ldots \ldots \\
=\quad \lambda_{0}+\lambda_{\mathrm{t}} \mathrm{RER}_{\mathrm{t}-1}+\sum \mathrm{c}_{\mathrm{i}} \Delta \mathrm{RER}_{\mathrm{t}-\mathrm{i}}+\varepsilon_{\mathrm{t}} \ldots \ldots \ldots \ldots \ldots \ldots \ldots \ldots \ldots \ldots \ldots \ldots \ldots\end{array}$ \\
\hline$\triangle \mathrm{RER}_{\mathrm{t}}$ & & $=\quad \lambda_{0}+\lambda_{\mathrm{t}} \mathrm{RER}_{\mathrm{t}-1}+\sum \mathrm{c}_{\mathrm{i}} \Delta \mathrm{RER}_{\mathrm{t}-\mathrm{i}}+\varepsilon_{\mathrm{t}}$ \\
\hline$\triangle \mathrm{QFERT}_{\mathrm{t}}$ & $=$ & $\mathrm{s}_{0}+\mathrm{s}_{\mathrm{t}}$ QFERT $_{\mathrm{t}-1}+\Sigma \mathrm{s}_{\mathrm{i}} \Delta \mathrm{QFERT}_{\mathrm{t}-\mathrm{i}}+\varepsilon_{\mathrm{t}}$ \\
\hline$\Delta \mathrm{PF}_{\mathrm{t}} / \mathrm{PC}_{\mathrm{t}}$ & $=$ & $\mathrm{u}_{0}+\mathrm{u}_{\mathrm{t}} \mathrm{PF}_{\mathrm{t}} / \mathrm{PC}_{\mathrm{t}-1}+\sum \mathrm{u}_{\mathrm{i}} \Delta \mathrm{PF}_{\mathrm{t}} / \mathrm{PC}_{\mathrm{t}-\mathrm{i}}+\varepsilon_{\mathrm{t}} \ldots$. \\
\hline $\begin{array}{l}\triangle \text { TRUSE }_{t} \\
\Delta \mathrm{IRRG}_{\mathrm{t}}\end{array}$ & $=$ & $\begin{array}{c}\mathrm{v}_{0}+\mathrm{v}_{\mathrm{t}} \text { TRUSE }_{\mathrm{t}-1}+\sum \mathrm{v}_{\mathrm{i}} \Delta \text { TRUSE }_{\mathrm{t}-\mathrm{i}}+\varepsilon_{\mathrm{t}} \ldots \ldots \ldots . . \\
=\quad \mathrm{z}_{0}+\mathrm{z}_{\mathrm{t}} \text { IRRG }_{\mathrm{t}-1}+\sum \mathrm{z}_{\mathrm{i}} \Delta \text { IRRG }_{\mathrm{t}-\mathrm{i}}+\varepsilon_{\mathrm{t}} \ldots \ldots\end{array}$ \\
\hline
\end{tabular}

$$
=\mathrm{z}_{0}+\mathrm{z}_{\mathrm{t}} \mathrm{IRRG}_{\mathrm{t}-1}+\sum \mathrm{z}_{\mathrm{i}} \Delta \mathrm{IRRG}_{\mathrm{t}-\mathrm{i}}+\varepsilon_{\mathrm{t}}
$$


$\triangle$ CRED $_{\mathrm{t}}=\mathrm{x}_{0}+\mathrm{x}_{\mathrm{t}} \mathrm{CRED}_{\mathrm{t}-1}+\sum \mathrm{x}_{\mathrm{i}} \Delta \mathrm{CRED}_{\mathrm{t}-\mathrm{i}}+\varepsilon_{\mathrm{t}}$

$\Delta$ RAINF $_{\mathrm{t}}=\mathrm{p}_{0}+\mathrm{ptRAINFt}_{-1}+\Sigma \mathrm{p}_{\mathrm{i}} \Delta \mathrm{RAINF}_{\mathrm{t}-\mathrm{i}}+\varepsilon_{\mathrm{t}}$

Where $\Delta$ is the first difference operator, $\varepsilon_{\mathrm{t}}$ is the stochastic error term that follows the classical assumptions. The other variables in equations (2) through (9) remain as defined in equation (1). The null hypothesis in equations (1) through (9) is that unit root exists, that is,

$\lambda_{1}=\phi_{1}=\mathrm{s}_{1}=\mathrm{u}_{1}=\mathrm{v}_{1}=\mathrm{z}_{1}=\mathrm{x}_{1}=\mathrm{p}_{1}=1$

against the alternative hypothesis, that

$\lambda_{1} \neq \phi_{1} \neq \mathrm{s}_{1} \neq \mathrm{u}_{1} \neq \mathrm{v}_{1} \neq \mathrm{z}_{1} \neq \mathrm{x}_{1} \neq \mathrm{p}_{1}<1$

The decision rule here follows the tau statistic computed on the basis of Monte Carlo Simulations. The t-test under the null hypothesis, which emphasizes the existence of unit root, is not applicable since the value of the estimated AR (1) coefficient does not follow the t-distribution even in large samples.

The general representation for equations (1) through (9) is:

$\Delta \mathrm{Y}_{\mathrm{t}}=\beta+\beta_{\mathrm{i}} \mathrm{t}+\delta_{\mathrm{i}} \mathrm{Y}_{\mathrm{t}-1}+\alpha_{\mathrm{i}} \Sigma \Delta \mathrm{Y}_{\mathrm{t}-\mathrm{i}}+\varepsilon_{\mathrm{t}}$

where

$\mathrm{Y}_{\mathrm{t}} \quad=\quad$ time series variable

$\beta \quad=$ drift parameter

$\beta_{\mathrm{I}}, \delta_{\mathrm{I}}$ and $\alpha_{\mathrm{i}} \quad=\quad$ coefficients

$\Delta \quad=$ difference operator

$\varepsilon_{\mathrm{t}} \quad=\quad$ white noise error term with zero mean and constant variance

$\Delta \mathrm{Y}_{\mathrm{t}-1}=\left(\mathrm{Y}_{\mathrm{t}-1}+\mathrm{Y}_{\mathrm{t}-2}\right), \Delta \mathrm{Y}_{\mathrm{t}-2}=\left(\mathrm{Y}_{\mathrm{t}-2}+\mathrm{Y}_{\mathrm{t}-3}\right)$ etc, that is, using lagged difference terms. The number of lagged difference term to include is often determined empirically, the idea being to include enough terms so that the error term is serially independent (Gujarati, 1995).

Step ii: Variables of the same order of integration are used to estimate the cointegration regression involving fertilizer demand functions implicitly stated in equation (1) using OLS method.

Step iii: The residuals of the cointegration regressions are tested for stationarity using the ADF test. The stationarity of the residuals indicates that the variables are cointegrated. This implies that quantity of fertilizer demanded, relative price ratios of fertilizer with respective crop prices and the other independent variables are in stable, predictable long-run equilibrium relationship

Step iv: This involves estimating the error correction model. The ECM to be estimated is given in the equation below:

$$
\begin{aligned}
\Delta \text { QFERT }_{\mathrm{t}}=\beta_{0} & +\beta_{1} \Delta \mathrm{QFERT}_{\mathrm{t}-1}+\beta_{2} \Delta \mathrm{PF}_{\mathrm{t}} / \mathrm{PC}_{\mathrm{t}}+\beta_{3} \Delta \mathrm{PF}_{\mathrm{t}} / \mathrm{PC}_{\mathrm{t}-1}+\beta_{4} \Delta \mathrm{RER}_{\mathrm{t}} \\
& +\beta_{5} \Delta \mathrm{HVAR}_{\mathrm{tt}}+\beta_{6} \Delta \mathrm{TRUSE}_{\mathrm{t}}+\beta_{7} \Delta \mathrm{IRRG}_{\mathrm{t}}+\beta_{8} \Delta \mathrm{IRRG}_{\mathrm{t}-1} \\
& +\beta_{9} \Delta \mathrm{CRED}_{\mathrm{t}}+\beta_{16} \Delta \mathrm{RAINF}_{\mathrm{t}}+\beta_{18} \Delta \mathrm{DUM}_{\mathrm{t}} \\
& +\beta_{19} \Delta \mathrm{ECM}_{\mathrm{t}-}+\mathrm{U}_{\mathrm{t}} \ldots \ldots \ldots \ldots \ldots \ldots \ldots \ldots \ldots \ldots \ldots \ldots \ldots \ldots \ldots \ldots \ldots \ldots \ldots \ldots \ldots \ldots \ldots \ldots \ldots \ldots \ldots \ldots \ldots \ldots \ldots \ldots \ldots \ldots \ldots \ldots \ldots \ldots \ldots
\end{aligned}
$$

Where,

$\Delta$ is the difference operator; ECM is the error correction mechanism.

The other variables remain as defined earlier. 


\section{EMPIRICAL RESULTS AND DISCUSSION}

Unit root test: the summary of unit root test is presented in table 1 .

Table 1: Unit Root Test

\begin{tabular}{ll}
\hline Variable & ADF \\
\hline$\Delta$ InQFERT & -3.2402 \\
$\Delta$ InPFC & -4.3822 \\
$\Delta \Delta$ InHAC & -6.9687 \\
$\Delta$ InIRG & -6.1434 \\
$\Delta \Delta$ InRER & -6.1434 \\
$\Delta$ InCRED & -3.0397 \\
$\Delta$ InTRUSE & -6.4752 \\
$\Delta$ InRAINF & -4.5856
\end{tabular}

Notes: Critical values for ADF at $5 \%=-1.953$, at $1 \%=-2.642$

$\Delta$ denotes order of integration, In is the natural log notation

The unit root test with trend using ADF ascertained that the entire variables are nonstationary in levels form. All the model variables are integrated of order one that is I(1) with the exception of Real Exchange Rate (RER) and the Harvest Area for cassava (HAC), which are both integrated of order two I(2). In all, the time series variable achieve stationarity at order 1 usually denoted I (1) and order 2 denoted I (2) that is after first and second differencing respectively. Stationarity of time series variables means that the mean, variance and autocovariance (given various lag lengths) remain the same no matter at what point they are measured, that is, they are time invariant. The implication of this process as noted in our methods is to avoid the consequences of regressing non-stationary time series with the antecedent problems of spurious results. With the result so achieved, the possibility to generalize our results in the final estimated model to other time periods has been achieved. The presence of unit root in the series at their levels form was eliminated through successive differencing.

Summary of Cointegration Test: the cointegration test result is presented in table 2.

\section{Table 2: Cointegration Test Estimates}

\begin{tabular}{ll}
\hline Variable & ADF \\
Residual & -4.0325 \\
\hline
\end{tabular}

Notes: Critical values for ADF at $5 \%=-1.953,1 \%=-2.645$

The linear combination of the variables integrated of the same order with the dependent variable confirmed cointegration between fertilizer demand and the exogenous variables since the residual generated is greater than the critical value, hence I (0). These results thus reject the null hypothesis of non-cointegration. In summary, the cointegration test result shows that there is a long-run equilibrium relationship between the dependent variable (quantity of fertilizer demanded annually) and the exogenous variables. This implies that fertilizer use adjusts to the changes in relative price of fertilizer-cassava and that of other variables in the models. Having established cointegration, the lagged residuals from the cointegrating regression I (0) can then used as the error correction mechanisms in the dynamic error correction model. The estimated parameters of an error correction model of fertilizer demand are presented in table 3 . 


\section{Error Correction Estimates}

Table 3 shows the results of the ECM estimates of the fertilizer demand equation. The joint influence of the explanatory variables in the above model is $41 \%$. The Durbin-Watson ratio statistics was computed and the hypothesis of no autocorrelation against positive autocorrelation was tested. With a ratio value of 1.91 , implying no autocorrelation at $1 \%$ probability level. The coefficients are consistent with the expected a priori signs. The only exception is fertilizer subsidy policy and rainfall. The coefficient of rainfall was significant at the 5 percent level while the subsidy coefficient was not significant.

Table 3: Estimated parameters of an error correction

\begin{tabular}{|c|c|c|}
\hline Explanatory variable & Coefficient & t-value \\
\hline$\Delta$ InQFERT $_{\mathrm{t}-1}$ & 0.272 & 0.716 \\
\hline$\Delta \mathrm{InPFC}_{\mathrm{t}}$ & -0.234 & $-2.291 * *$ \\
\hline$\Delta \mathrm{InPFC}_{\mathrm{t}-1}$ & 0.031 & 0.104 \\
\hline$\Delta \Delta \operatorname{InHAC}_{\mathrm{t}}$ & 0.394 & $1.757 *$ \\
\hline$\Delta \operatorname{InIRG}_{\mathrm{t}}$ & 1.635 & $1.995^{*}$ \\
\hline$\triangle \mathrm{InCRED}_{\mathrm{t}}$ & 0.008 & 0.066 \\
\hline$\Delta$ InTRUSE $_{\mathrm{t}}$ & 0.936 & $2.818 * *$ \\
\hline$\Delta \Delta \operatorname{InRER}_{\mathrm{t}}$ & -0.106 & -1.206 \\
\hline$\Delta \operatorname{InRAINF}_{\mathrm{t}}$ & -0.734 & $-2.25 * *$ \\
\hline DUM & -0.089 & -0.065 \\
\hline $\mathrm{ECM}_{-1}$ & -0.22 & -0.857 \\
\hline $\mathrm{R}^{2}$ & 0.41 & \\
\hline DW & 1.91 & \\
\hline
\end{tabular}

The relative price coefficient (fertilizer to cassava price ratio) is consistent with a priori expected signs and statistically significant at the 5 percent level. This result indicates that when the real price of fertilizers increases by 10 percent, farmers in Nigeria decrease fertilizer use by 2.3 percent in the short-run. The less than proportionate fall in demand as suggested by the findings above confirms Parthasarathy (1994) assertion that the rising trend in fertilizer consumption in many developing countries cannot be fully explained by the inputoutput price relationship alone. The report however recognized that increasing benefit opportunities given by high yielding varieties and extended irrigation systems, even in the face of adverse fertilizer-crop price ratio supports the trend. These facts gain credence when viewed against the background of demographic realities and market perspectives. The rising populations in the country and the massive rural-urban drift of people have a sort of structural effect on agriculture, which has created significant effect on employment and market competitiveness. In quest for urban livelihood, agricultural labor force has been depleting at a very fast rate, thus living just few members of the house hold on the farm. It follows logically that this reduced manpower can only gain efficiency through the application of external inputs such as fertilizer. The case of market competitiveness in this discourse presents a contrasting picture of the alternative situation where many hands would have been actively involved in farming with a consequent glut in production. In other words, a level of scarcity or decline in production will enhance the rate at which farm products are cleared off the farm gate. This by extension will reduce the costs of storage and spoilage, hence creating extra income to purchase in fertilizers. In summary, demand for fertilizers depends on many salient factors, which however may have an indirect linkage with relative price. To buttress this 
assertion, the result obtained in this study further shows that irrigation and tractor in use exert a positive and statistical significant effect on the use of fertilizer. The use of these inputs also depends on their relative scarce values as coordinated by their prices. It also shows the interrelatedness and complementarities in their use. Modak and Barmon (1996) and Mergos and Stoforos (1997) variously reported a positive and statistical significant effect of irrigation and expansion of irrigation on fertilizer demand respectively.

The relationship between the harvest area of cassava and fertilizer demand, which was positive and significant at $10 \%$, indicates that a 10 percent increase in harvest area of cassava leads to a $3.9 \%$ increase in fertilizer demand in the short-run. The lagged effect of fertilizer use and that of relative fertilizer price had positive but insignificant effect on fertilizer demand. Finally, the ECM coefficient suggests that the speed of adjustment of the model is $22 \%$. This is the error corrected each year due to the disequilibrium between the short-run and long-run dynamics of the model. The test result of 22 percent of the adjustment rate is rather low. It upholds a number of implications arising mainly from a perceived lag in response of fertilizer-use to shifts and shocks in the determinant variables. This lag in response is associated with inherent operational difficulties in agriculture in that an operation cycle must be completed irrespective of contingencies. For instance, farmers who had already initiated a cultivation process, only to observe a sudden rise in fertilizer price, may not be able to adjust fertilizer-use immediately. Following the highly reported cases of variability in the prices of fertilizer, it becomes increasingly difficult for farmer's to take an instantaneous and speedy adjustment in the use of fertilizer.

\section{Relative Price Elasticities of Fertilizer to Cassava Price Ratio}

Table 4 shows the summary of short-run and long-run price elasticity of fertilizer demand.

\section{Table 4: Estimated Relative Price Elasticities}

\begin{tabular}{lll}
\hline & Short run & Long run \\
$\begin{array}{l}\text { Price ratios of fertilizer and }-0.23 \\
\text { cassava }\end{array}$ & -0.60 \\
\hline
\end{tabular}

\section{Source: Extrapolated from the ARDL-ECM Analysis}

The short-run relative price elasticity of fertilizer demand in Nigeria was estimated at -0.23 percent and the long-run elasticity at -0.60 percent. These estimates are slightly lower compared to own price elasticities estimated by Ogunfowora (1987) for developing countries, which range from -0.26 to -0.9 for short-run and -0.8 to -1.76 for long-run. The higher value of long-run elasticity provided by this study is consistent with that of Modak and Barmon (1996) in their fertilizer demand study for Bangladesh. They indicate that the presence of higher value long-run elasticity implies that in the long-run, the farmers would be more sensitive to use fertilizer when the price of fertilizer increases. The policy implication of this finding is that it is more effective to raise fertilizer use through an increase in crop output prices rather than a fertilizer subsidy scheme that would hardly reach the target beneficiaries. To engender quick intervention, it behooves policy makers to foster measures that will raise soil productivity in order to bridge food supply gap. This supply gap among other factors has a strong bearing on the poor productivity of soils in Nigeria. Bukar, et al (1997) asserted that 48 percent of Nigerian soils according to FAO ratios have been categorized as having low productivity, thus a proper management and improvement of the inherent fertility of Nigerian soils hold the key to sustainable agricultural production. This invariably means that alternatives other than chemical fertilizers are likely to be used as substitutes.

\section{CONCLUSION}


The findings of this study demonstrate that the demand for fertilizer exhibits a stable long-run equilibrium relationship with its relative price and other explanatory variables in the model. Fertilizer demand adjusts to the long-run equilibrium path slowly following disturbance and shocks in the determinants. In essence, the cointegrataion of the model variables and the significance of the error term are confirmed. Further confirmation has also been obtained regarding the responsiveness of fertilizer demand to relative price changes both in the shortrun and long-run. By implication, the challenge is how to build efficiency into fertilizer distribution and pricing through efficient market information system that will strategically link farmers to inputs and outputs markets. If farmers are provided with adequate information about target markets and price situation, they will able to respond with relatively higher speed and precision to obviate the risk of income depression arising from unfavorable input-output price shifts.

Increased concern on technology-driven agriculture is somewhat implicit in this study with the positive correlation between fertilizer use and irrigation. In this connection, emphasis must be placed on policies to further develop irrigation infrastructure across the country. A Private-Public--Partnership (PPP) approach can be adopted in this regard with the overall objective of reducing high costs of development and maintenance while achieving high level of efficiency in the short and long-run. Though the study did not investigate an empirical link between the use of improved seed varieties and fertilizers, it only goes without saying that a positive correlation does exist. It is not evident that much is being done in the area of seed improvement and preservation of germplasm in Nigeria. Evidence of research abounds to show that improved cultivars respond more favorably to fertilizer use than local ones. Interventions are therefore needed to build greater capacity for developing improved cultivars and crop protection practices without which fertilizer use efficiency will remain very low.

\section{REFERENCES}

Binswanger, H.P (1986) Evaluating Research System Performance and Targeting Research in Land-abundant Areas of Sub-Saharan Africa. World Development 14, 469-476

Binswanger, H.P. (1990) The Policy Response of Agriculture. Proceedings of the World Bank Annual Conference on Development Economics, World Bank Washington D.C, Pp. 231-271

Bukar, S., A. Adamu and J.S. Bakshi (1997) National Agricultural Research Strategy Plan: 1996-2010. Dept. of agricultural Sciences, Federal Ministry of Agriculture and Natural Resources.

Central Bank of Nigeria (2001) Statistical Bulletin, CBN/FGN, Abuja Nigeria

Dickey, D.A. and W.A. Fuller (1976) Distribution of the Estimators for Autoregressive Time Series with a Unit Root. Journal of The American Statiscal Association, Vol. 74, pp427-431

Emerole, C. and J.O. Chima (1998) Fertilizer Subsidy Withdrawal-Experience and Challenges to Arable Crop Producers in Abia State. An unpublished paper presented at $32^{\text {nd }}$ annual conference of the Agricultural Society of Nigeria, held at Federal College of Agriculture, Ishiagu Ebonyi State, September, 1998 
Eicher, C.K. (1995) Zimbabwe's maize-based green revolution preconditions for replication. World Development, 23(5): 805-818

Engle, R.F and C.W.J. Granger (Eds) (1987) Cointegration and Error Correction Representation, Estimation and Testing. Econometrica 55, 251-76

Gujarati, D.N. (1995) Basic Econometrics ( $3^{\text {rd }}$ Edition) McGraw Hill, Inc., Singapore

Mergos, G. J. and C. E. Stoforos (1997) Fertilizer Demand in Greece. Agricultural Economics 16 (1997) 227-235. Dept of Agricultural Economics, University of Athens, Greece.

Modak, P.C. and B.K. Barmon (1996) Demand for Fertilizer in Bangladesh-A Note. Bangladesh J of Agric Econs Xix, 1 and 2: 97-103

Ogunfowora, O. (1987) Fertilizer Policy and Program in Nigeria. Proceedings of the National Fertilizer Seminar held in Port Harcourt October 28-30, 1987. Towards Efficiency of Fertilizer Use and Development in Nigeria. Organized by fertilizer Procurement and Distribution Department (FPDD).

Parthasarathy, N.S. (1994) Demand Forecasting for Fertilizer Marketing. FAO, Rome

Tanko, L. (2001) Effect of Subsidy Withdrawal on Fertilizer Demand and Agricultural Production in Kebbi State, Nigeria. M.Sc. Thesis, Michael Okpara University of Agriculture, Umudike.

Timmer, C.P., (1986) 'The Role of Price in Rice Production In Indonesia 1968-1982'. In Research in Domestic and International Agribusiness Management. Goldberg R.A (Ed) Pp. 55-106, Greenwich Con Press

Viyas, V.S. (1983) Asian Agriculture: Achievement and Challenges. Asian. Development Review, 1 (1): 27-44 